\title{
Role of the Autonomic Nervous System in the Circulatory Response to Acutely Induced Anemia in Unanesthetized Dogs*
}

\author{
Gerald Glick, $\dagger$ William H. Plauth, Jr., and Eugene Braunwald with \\ THE TECHNICAL ASSISTANCE OF Hope COOK AND Robert M. Lewis
}

(From the Cardiology Branch, National Heart Institute, Bethesda, Md.)

Studies in patients with chronic anemia and in anesthetized animals rendered anemic have demonstrated that, within wide limits, cardiac output rises as the hematocrit falls (1-5). The fundamental importance of the autonomic nervous system in circulatory regulation in the intact organism (6) influenced us to determine its role in the profound hemodynamic changes that occur during the stress of acutely induced isovolemic anemia. The basic objective of this study was to compare the circulatory responses to acutely induced isovolemic anemia in normal dogs with the responses observed in animals in which the control exerted by the autonomic nervous system had been impaired, either by chronic total cardiac denervation or by reserpine. Most previous experiments on acutely induced anemia have been carried out on anesthetized animals (2-5), in which many compensatory reflex mechanisms must, of necessity, have been either obtunded or ablated. To obviate this problem, the present investigation was carried out on trained, unanesthetized dogs.

\section{Methods}

The studies were performed on dogs weighing between 13.0 and $22.3 \mathrm{~kg}$. With the dog under local anesthesia, catheters were introduced into the right atrium via the jugular vein and into the aorta through the femoral artery. Isovolemic anemia, to an average hematocrit of $13.6 \% \pm 0.3 \%$ (standard error of the mean SEM), was produced by withdrawing blood from the aortic catheter and simultaneously replacing it with an equal volume of $6 \%$ dextran ${ }^{1}$ injected into the right atrium. This exchange required 10 to 15 minutes, and particular care was taken to ensure that no changes in blood volume occurred. Cardiac output was meas-

* Submitted for publication April 13, 1964; accepted July $9,1964$.

$\dagger$ Established Investigator, American Heart Association.

1 Cutter Laboratories, Berkeley, Calif. ured during the control period and 15 minutes after the completion of the blood-for-dextran exchange by the indicator-dilution technique, with injection of indocyanine green into the right atrium and sampling from the aorta. Blood was drawn through a cuvette densitometer : at the rate of $37.5 \mathrm{ml}$ per minute, while the dilution curves were inscribed on a linear chart recorder. The blood was returned to the animal immediately after withdrawal. All determinations of cardiac output were performed in duplicate, the paired values differing by an average of $12.3 \% \pm 9.1 \%$ (SD) from one another. Separate dye calibration curves were constructed for the normal and for the anemic blood. Pressures were recorded from the right atrium and aorta immediately after each measurement of cardiac output. Arterial blood samples were collected during each period for measurement of hematocrit and for determination of $\mathrm{O}_{2}$ content and capacity and of $\mathrm{CO}_{2}$ content by the method of Van Slyke and Neill (7). The hematocrit values were not corrected for trapped plasma. Arterial blood $\mathrm{pH}$ and $\mathrm{PCO}_{2}$ were determined with a glass electrode. ${ }^{3}$ Total systemic resistance (TSR) in dynes-sec- $\mathrm{cm}^{-5}$ was calculated as follows:

$$
\mathrm{TSR}=\frac{\begin{array}{c}
\text { systemic arterial mean pressure } \\
(\text { millimeters } \mathrm{Hg})-\text { right atrial mean } \\
\text { pressure (millimeters } \mathrm{Hg})] \times 1,332
\end{array}}{\text { cardiac output (milliliters per second) }} .
$$

Left ventricular minute work (LVMW) in gram-meters per minute per kilogram was derived as follows: $\mathrm{LVMW}=[$ systemic arterial mean pressure (centimeters $\mathrm{H}_{2} \mathrm{O}$ ) -6.8$] \times$ cardiac index (liters per minute per kilogram $) \times 10$, where $6.8 \mathrm{~cm} \mathrm{H} \mathrm{H}_{2} \mathrm{O}(5 \mathrm{~mm} \mathrm{Hg})$ is assumed to be the left ventricular end-diastolic pressure. Left ventricular stroke work in gram-meters per beat per kilogram was obtained by dividing left ventricular minute work by the heart rate. Oxygen delivery in milliliters per minute per kilogram to the tissues was calculated as follows: $\mathrm{O}_{2}$ delivery $=$ arterial $\mathrm{O}_{2}$ content (volumes per $100 \mathrm{ml}$ ) $\times$ cardiac index (milliliters per minute per kilogram).

Seven animals served as controls and will be referred to as "intact" dogs. Eight dogs had been subjected to cardiac denervation by the regional neural

${ }^{2}$ Gilford Instrument Laboratories, Oberlin, Ohio.

3 Instrumentation Laboratory, Boston, Mass. 
ablation technique of Cooper, Gilbert, Bloodwell, and Crout (8) 4 to 6 months before study. This method of denervation isolates the heart from both the sympathetic and parasympathetic nervous systems. Three of the eight dogs that had been subjected to cardiac denervation were studied on another occasion after blockade of beta-adrenergic receptors by the intravenous administration of $5 \mathrm{mg}$ per $\mathrm{kg}$ nethalide 4 (2-isopropylamino-1-[2-naphthyl] ethanol hydrochloride). The studies with nethalide were performed on the animals 5 to 7 months after the initial, experiment. As indicated in Table III, the dogs were no longer anemic. Both the control measurements and those after anemia had been induced were carried out immediately after the administration of nethalide.

At the time of each experiment the completeness of the denervation was verified by studying the response to the intravenous injections of tyramine ( $40 \mu \mathrm{g}$ per $\mathrm{kg}$ ) and norepinephrine $(0.5 \mu \mathrm{g}$ per $\mathrm{kg})$. Tyramine, which acts by releasing norepinepherine from myocardial stores $(9,10)$, did not produce a rise either in blood pressure or in heart rate in the dogs with denervated hearts, indicating that the cardiac catecholamine stores had been depleted as a consequence of denervation (8, 11). Norepinephrine produced marked hypertension and tachycardia instead of the usual bradycardia. It was therefore concluded that reflex slowing resulting from vagal stimulation or withdrawal of sympathetic activity had been eliminated; rather, the direct chronotropic effect of norepinephrine was observed (11). Finally, after the conclusion of this series of experiments, the right atrium was biopsied in seven of the eight dogs whose hearts had been denervated, and the norepinephrine concentrations were determined by the trihydroxyindole photofluorometric method, as detailed elsewhere (12). No detectable levels of norepinephrine were found in any specimen, confirming that complete adrenergic denervation had indeed been achieved.

In four dogs, generalized catecholamine depletion was produced by the intravenous administration of reserpine, $0.15 \mathrm{mg}$ per $\mathrm{kg}$, for 2 days before the study. Analysis of atrial tissue for catecholamine content in these dogs confirmed that complete catecholamine depletion had been produced. In two normal dogs and in five dogs with denervated hearts, plasma catecholamine levels were measured by the trihydroxyindole fluorometric method during the control period and 1 and 15 minutes after the end of the exchange transfusion. The reported statistical analyses of absolute changes were performed by Student's $t$ test (13). Similar results also were obtained when comparisons of percentage changes were made.

\section{Results}

During the control period the arterial hematocrit in the 22 studies on 19 dogs averaged $42.2 \%$

4 Supplied by Dr. Alex Sahagian-Edwards, Ayerst Laboratories, New York, N. Y. $\pm 1.0(\mathrm{SEM})$. Fifteen minutes after the bloodfor-dextran exchange the hematocrit averaged $13.6 \% \pm 0.3$. No significant differences among the hematocrit values after the production of anemia in the different groups of dogs were observed. During the control period the intact dogs and the dogs with denervated hearts did not differ significantly from each other in respect to cardiac index, $\mathrm{O}_{2}$ delivery, right atrial mean pressure, systemic arterial mean pressure, systemic vascular resistance, or left ventricular minute work. However, in the dogs with denervated hearts, the heart rates were significantly higher $(p<0.05)$, while the stroke index and the left ventricular stroke work index were each significantly lower $(p<0.05)$ than in the intact dogs.

Although after the production of anemia the dogs with denervated hearts showed a substantial increase in cardiac index that averaged $77 \%$, from a mean value of 173 to $309 \mathrm{ml}$ per minute per $\mathrm{kg}$, this rise was significantly less $(p<0.02)$ than that noted in the intact dogs, in which it increased by an average of $119 \%$, from a mean value of 175 to $379 \mathrm{ml}$ per minute per $\mathrm{kg}$ (Tables I and II, Figure 1). The manner in which the increase in cardiac output was mediated differed between the two groups of animals. Whereas in the intact animals the heart rate rose by an average of $83 \%$ from 108 to 196 beats per minute, it increased significantly less $(p<0.01)$ in the dogs with denervated hearts, rising by an average of only $23 \%$, from a mean of 132 to 161 beats per minute (Figure 1). In contrast, the changes in stroke index were more prominent in the dogs with denervated hearts. Thus, while in the intact dogs the stroke index increased by an average of only $21 \%$, from a mean value of 1.62 to 1.93 $\mathrm{ml}$ per beat per $\mathrm{kg}$, it rose significantly more $(p<0.04)$ in the dogs with denervated hearts, increasing by an average of $44 \%$, from a mean value of 1.32 to $1.90 \mathrm{ml}$ per beat per $\mathrm{kg}$.

A comparison of the relative importances of the augmentation of heart rate and stroke volume in the elevation of the cardiac output induced by anemia is represented graphically in Figure 2 . In the intact dogs the increase in cardiac output resulted primarily from an augmentation of heart rate and to a lesser extent from an elevation of stroke volume. In the dogs with denervated 
G. GLICK, W. H. PLAUTH, JR., AND E. BRAUNWALD

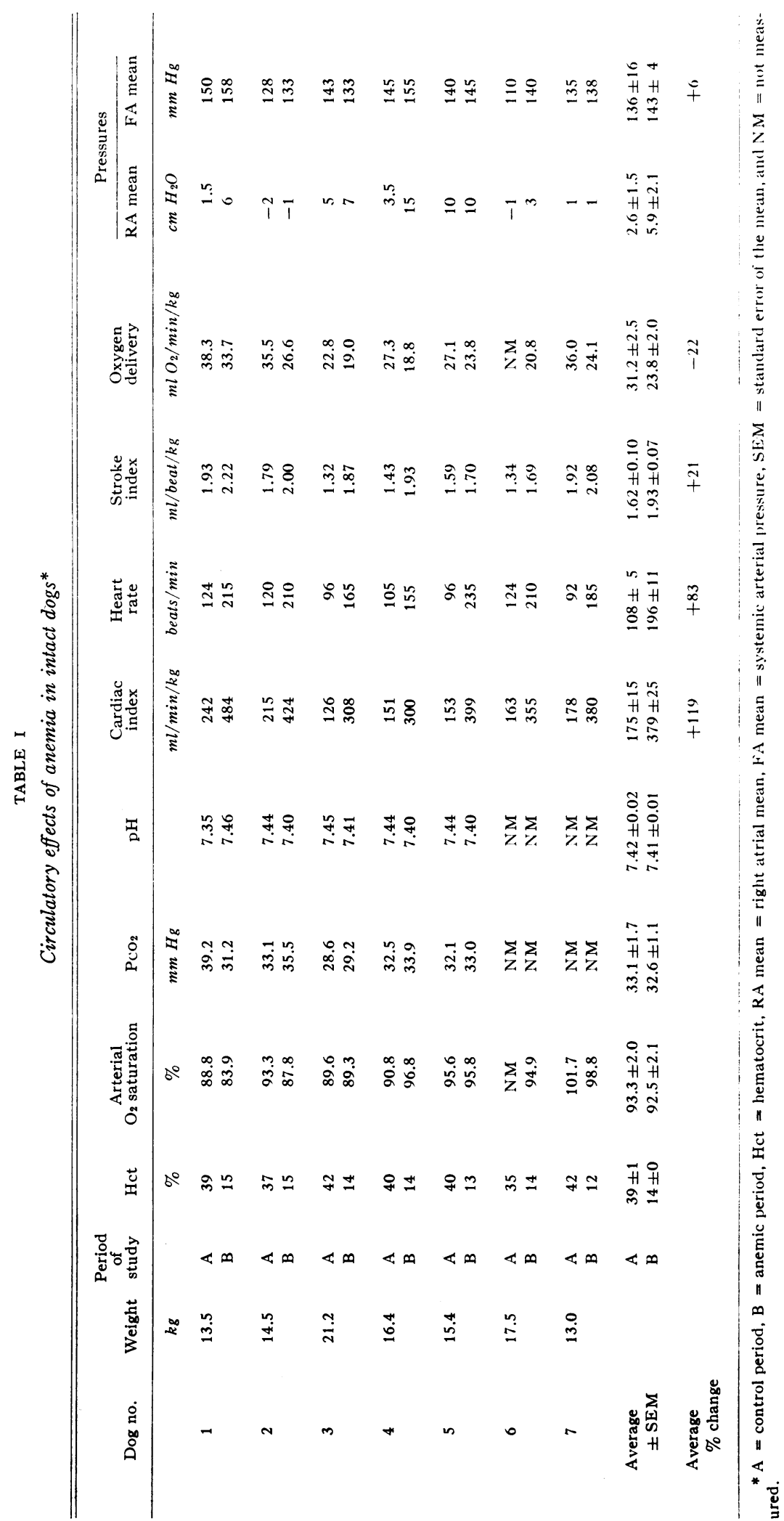




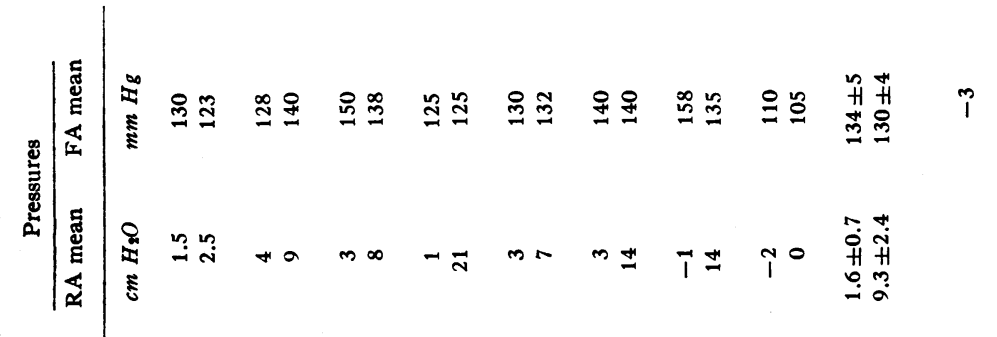

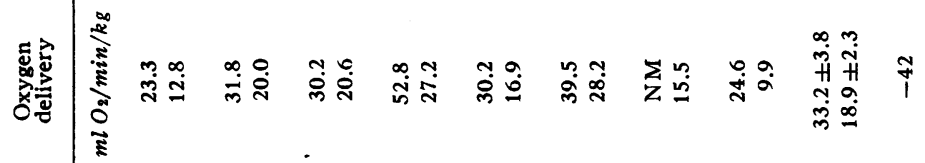
产总 苞苟

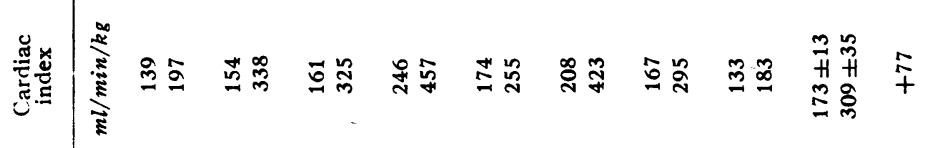

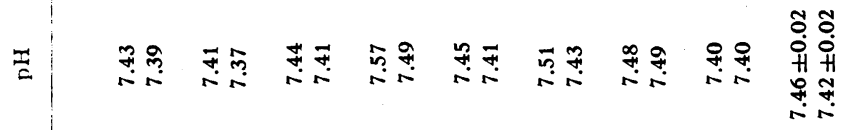

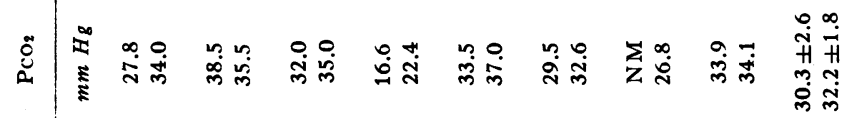

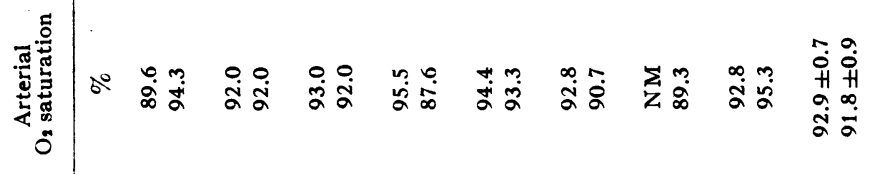

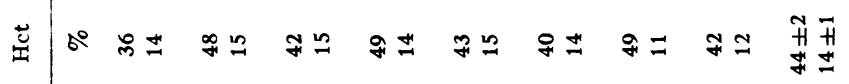

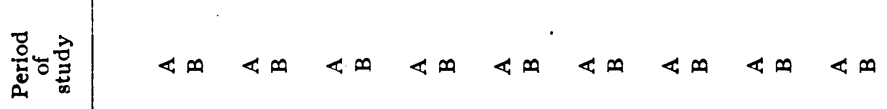
ஓं

它 $\begin{aligned} & \dot{0} \\ & \dot{0} \\ & \dot{0}\end{aligned}$ 

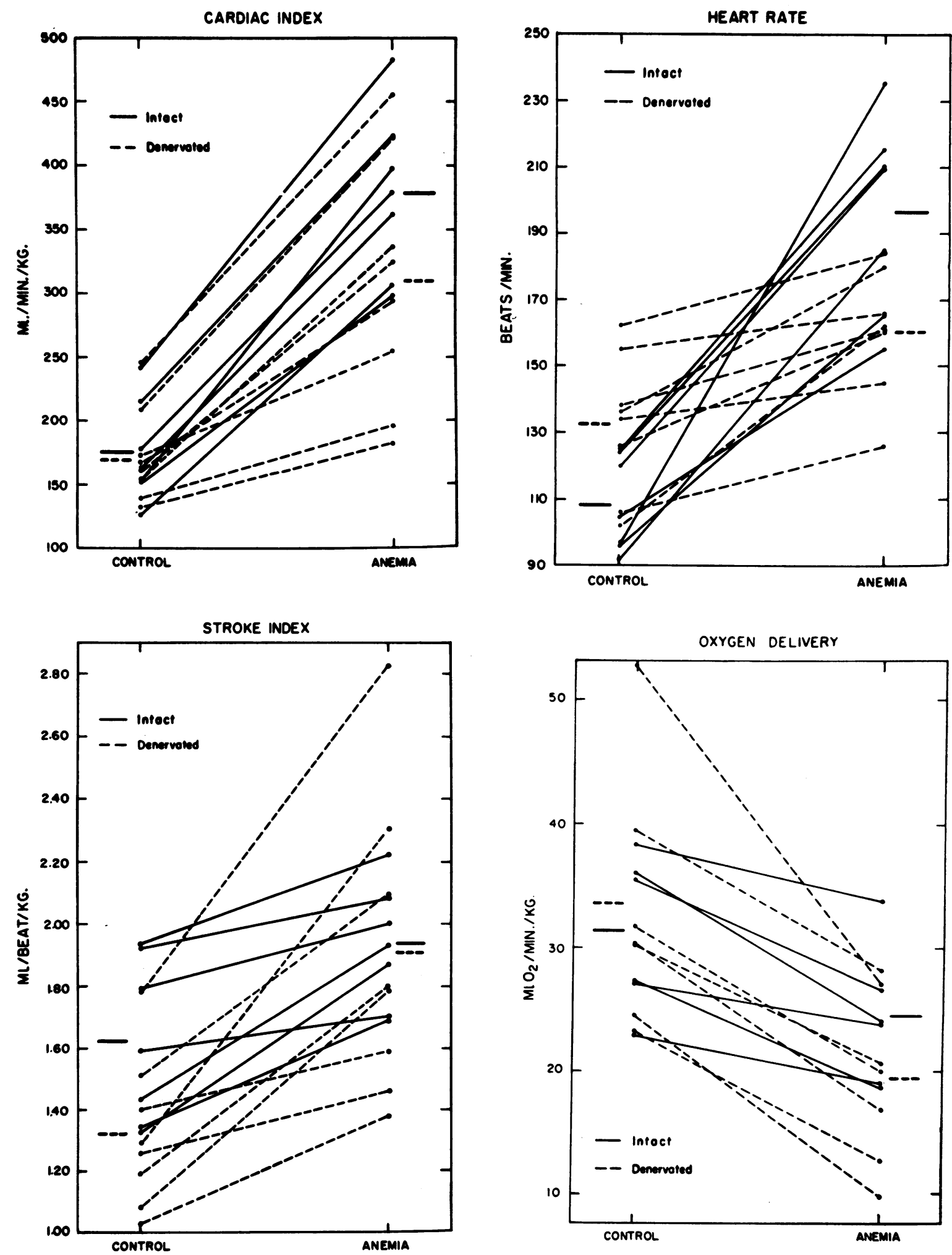

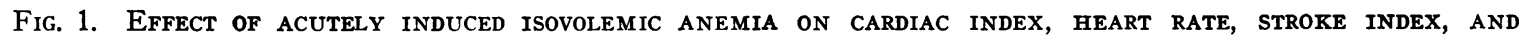
OXYGEN DELIVERY TO THE TISSUES. In each panel the values during the control period are plotted on the left, and the values after the production of anemia are on the right. The values in each individual experiment are connected by a solid line for the intact dogs and by a broken line for the cardiac denervated dogs. The horizontal lines on each side of the individual panels represent the mean values for each group of dogs. 
hearts there was a greater tendency for the increase in cardiac output to result primarily from an elevation of stroke volume than in the intact dogs.

Oxygen delivery to the tissues fell in all dogs in both of these groups (Figure 1). Thus, in no animal was the increase in cardiac output during anemia sufficient to maintain oxygen delivery to the tissues at control levels. In the intact dogs the oxygen delivery declined by an average of $22 \%$, from a mean value of 31.2 to $23.8 \mathrm{ml} \mathrm{O}$ per minute per $\mathrm{kg}$, whereas in the dogs with denervated hearts it decreased significantly more $(\mathrm{p}<0.01)$, falling by an average value of $42 \%$, from a mean value of 33.2 to $18.9 \mathrm{ml} \mathrm{O}_{2}$ per minute per $\mathrm{kg}$.

Anemia did not result in any consistent or significant changes in arterial mean pressure in either the intact dogs or in the dogs with denervated hearts (Tables I and II). Calculated systemic vascular resistance fell in each animal, declining in the intact animals by an average of $52 \%$, from a mean value of $3,991 \pm 246$ to a mean value of $1,902 \pm 107$ dynes-sec- $\mathrm{cm}^{-5}$. The fall in resistance was not significantly different in the dogs with denervated hearts, in which it fell by an average of $46 \%$, from a mean value of $3,344 \pm 192$ to 1,831 \pm 194 dynes-sec- $\mathrm{cm}^{-5}$ (Figure 3 ).

Anemia resulted in an increase of left ventricular stroke work that averaged $28 \%$ in the intact dogs, stroke work rising from a mean value of $2.89 \pm .23$ to $3.63 \pm 0.20 \mathrm{~g}-\mathrm{m}$ per $\mathrm{kg}$. In the dogs with denervated hearts stroke work rose from a mean value of $2.28 \pm .13$ to one of $3.27 \pm$ $0.33 \mathrm{~g}-\mathrm{m}$ per $\mathrm{kg}$, an average rise of $41 \%$, which was not significantly different from that noted in the intact dogs (Figure 3). Left ventricular minute work in the intact animals increased by an average of $131 \%$, from a mean value of $312 \pm 31$ to $711 \pm 56 \mathrm{~g}-\mathrm{m}$ per minute per $\mathrm{kg}$, a significantly greater $(p<0.01)$ elevation than in the cardiac denervated dogs, in which it rose an average of $74 \%$, from $304 \pm 26$ to $536 \pm 67$ g-m per minute per kg (Figure 3).

The right atrial mean pressure rose from an average of 2.6 to $5.9 \mathrm{~cm} \mathrm{H}_{2} \mathrm{O}$ in the intact dogs. Although the elevation in the dogs with cardiac denervation tended to be greater, the changes in right atrial mean pressure resulting from anemia were not significantly different in the two groups of animals. The changes in the $\mathrm{pH}$ and $\mathrm{PCO}_{2}$ of the arterial blood were small and comparable in the two groups of animals (Tables I and II). The changes in plasma epinephrine and norepinephrine concentrations induced by anemia in the two intact dogs and in the five dogs with denervated hearts in which they were determined were small and inconsistent.

The response to anemia in three dogs with denervated hearts was not prevented by blockade with nethalide (Table III). Thus, cardiac index, heart rate, and stroke index increased by averages of $95 \%, 20 \%$, and $60 \%$ in the presence of beta-blockade and cardiac denervation, whereas these variables rose by averages of $77 \%, 23 \%$, and $44 \%$ in dogs with cardiac denervation but without beta-blockade. The absolute values and the changes induced by anemia in these variables also were similar in these two groups of animals. Thus, although the limited number of experiments precludes a statistical comparison, betareceptor blockade did not appear to modify the response to anemia of the dogs with denervated hearts.

The absolute values for cardiac index and heart rate were uniformly lower in the dogs that had been given reserpine than in the intact dogs or in the dogs with denervated hearts, but no apparent differences in stroke index were noted (Table III). The absolute increases in cardiac index and heart rate resulting from anemia were less in the animals given reserpine than in the intact group, whereas the changes in stroke index in these two groups of dogs were of comparable magnitudes. When the responses to anemia of the dogs given reserpine were compared to those of the animals with cardiac denervation, however, no apparent differences in cardiac index, heart rate, or stroke index were observed (Tables II and III).

\section{Discussion}

The results of this investigation demonstrate that the cardiac output of the normal unanesthetized dog rises strikingly when the animal is subjected to acutely induced isovolemic anemia and thus are in agreement with the work of other investigators who have studied this state in anes- 


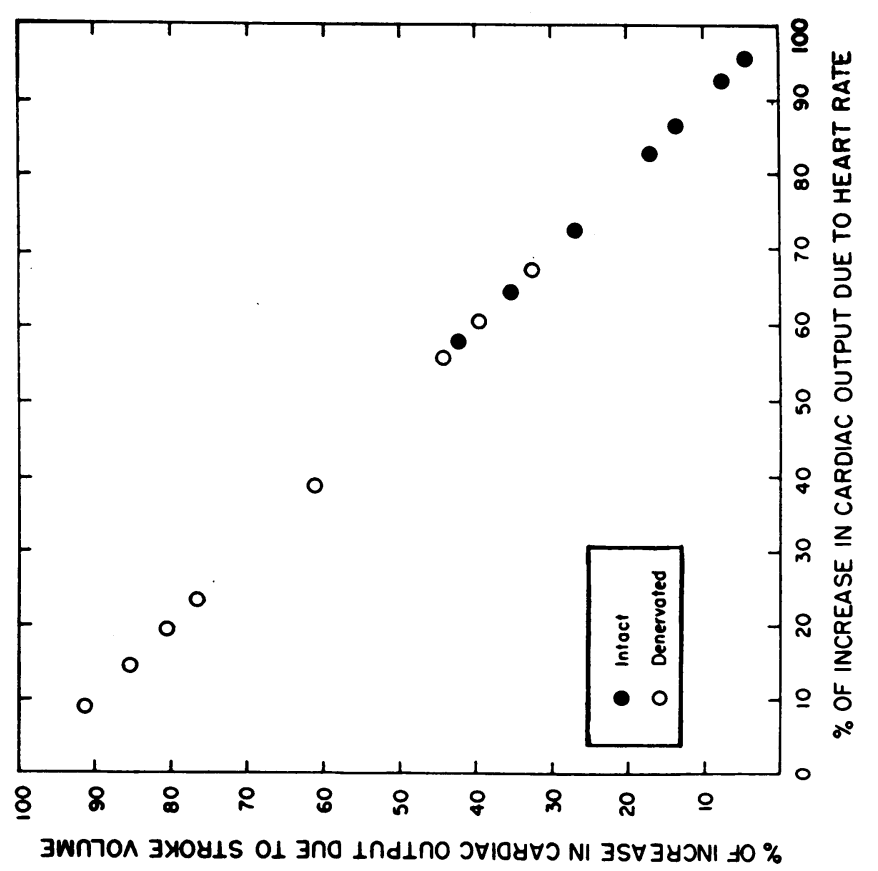

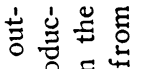

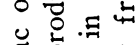

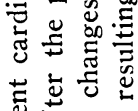

岕跑志

过总焉

थ

I 的

苍.

ำ

总充.

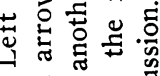

요웡

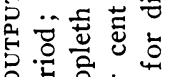

品范

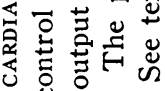

L./MIN.

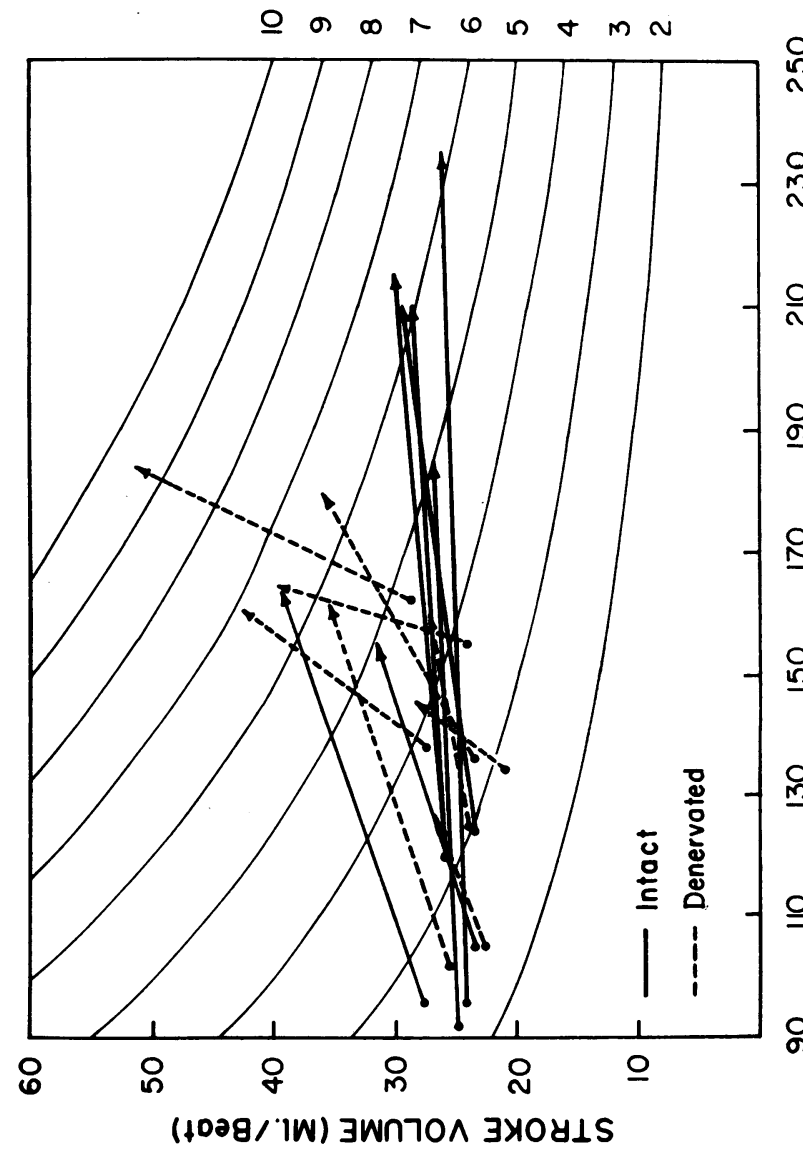

z

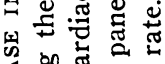

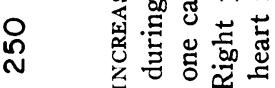

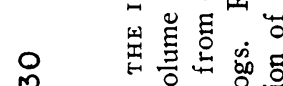

N ž

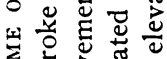

으 $\quad$ के

.

으

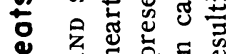

$\underline{0}<\dot{0}$

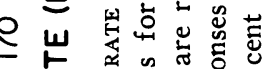

ه

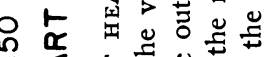

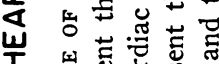

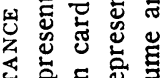

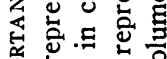

范总

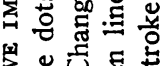

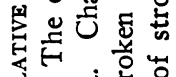

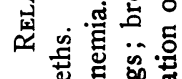

ง 党

i.

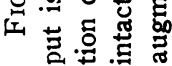




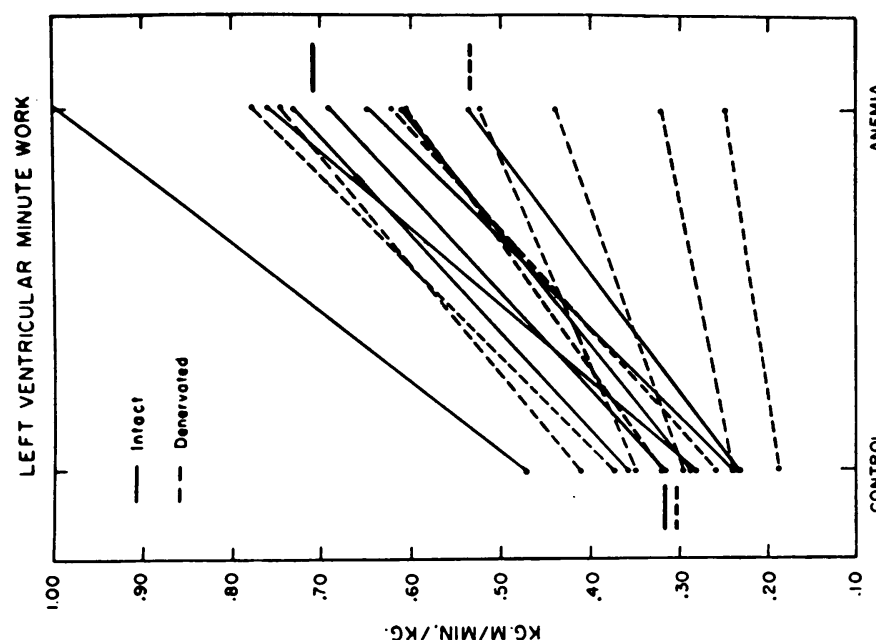

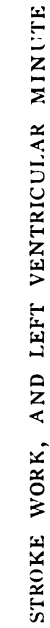

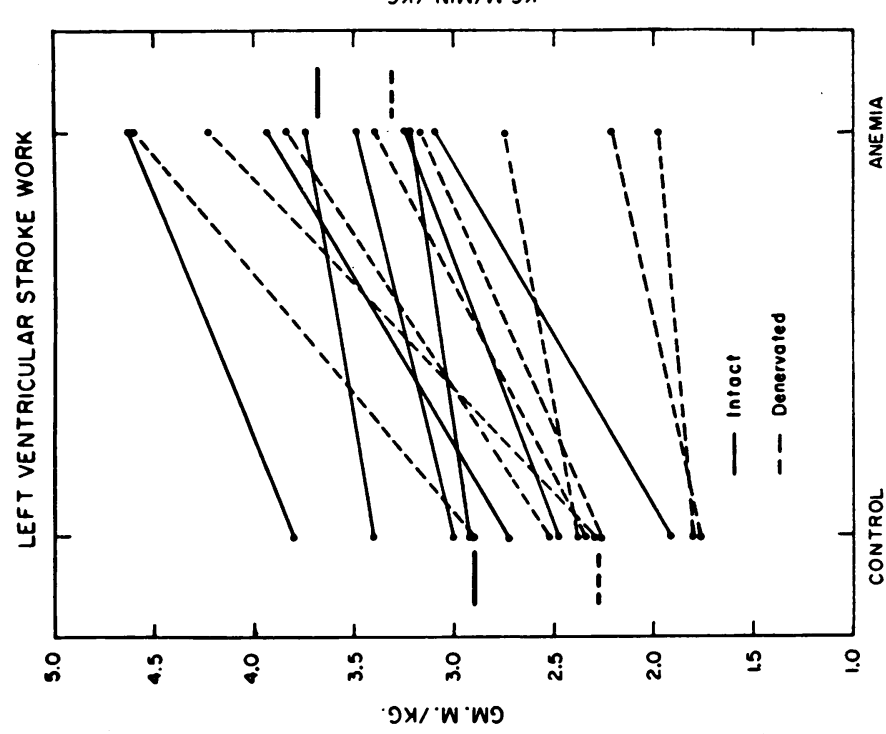

紊

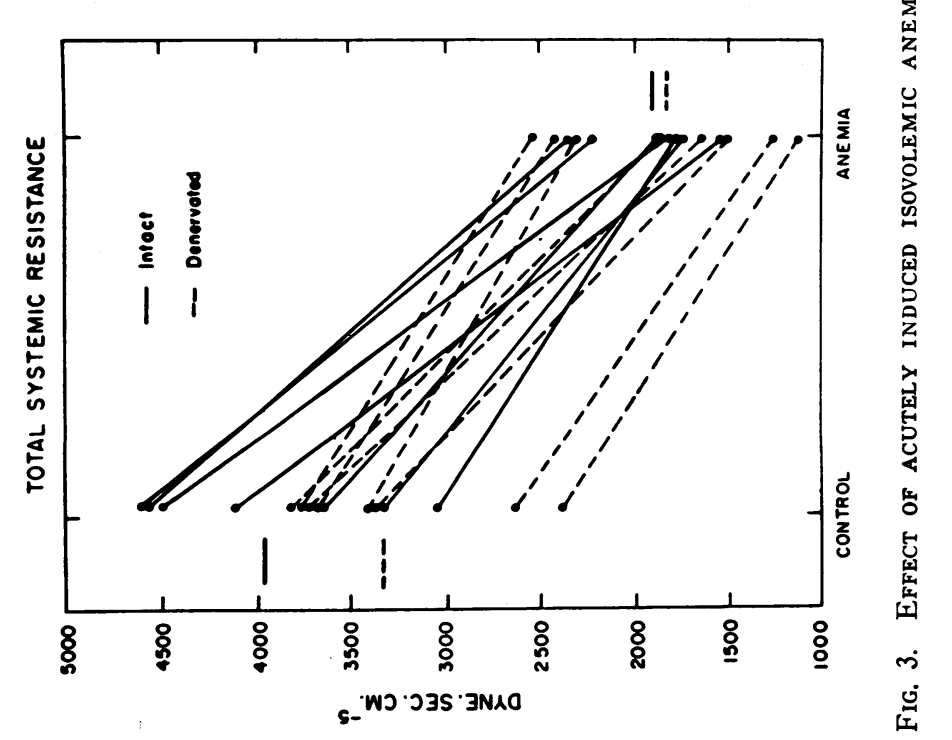


thetized animals (2-5). Although the mechanism responsible for this increase in cardiac output has not been elucidated, a number of possibilities have been suggested. These include a decrease in peripheral resistance resulting from a fall in blood viscosity and arteriolar dilatation, an elevation of right heart filling pressures, stimulation of chemoreceptors sensitive to a decreased partial pressure of oxygen, the action of a noncatecholamine humoral mediator, and the activity of the adrenergic nervous system (14-17). The present study was designed to examine the importance of the autonomic nervous system in the circulatory response to anemia.

It is well recognized that the use of general anesthesia and the depth and specific agent employed can profoundly alter the response of the autonomic nervous system. To obviate these problems it was necessary to perform these studies on trained, unanesthetized animals. To determine the role of the autonomic nervous system, the effects of anemia on dogs subjected to total chronic cardiac denervation were determined. Thoracic sympathectomy has been the traditional method of producing cardiac denervation (18, 19), but complete denervation and total myocardial catecholamine depletion are rarely produced by this operation $(8,20)$. Moreover, portions of the animal other than the heart are necessarily denervated by such a procedure, and the parasympathetic fibers of the vagus nerve are not included in the operation. Although cardiac denervation by pharmacologic agents that deplete the entire animal of norepinephrine have also been utilized, the entire circulatory system is depleted of catecholamines in this manner, making it difficult to assess the effects of the sympathetic cardiac nerves per se. The regional neural ablation technique employed in this study makes it possible to overcome these problems.

Dogs deprived of both the sympathetic and parasympathetic cardiac nerves were still capable of substantially increasing their cardiac output and left ventricular work when rendered acutely anemic. However, since the increases in cardiac index and minute work were significantly less in the dogs with denervated hearts than in the intact animals, the autonomic nervous system apparently plays a significant role in the circula- tory response to anemia. These observations are not consonant with the hypothesis that the increase in cardiac output produced by anemia may be attributable entirely to the fall in blood viscosity (14). It should be emphasized, however, that four of the eight dogs subjected to cardiac denervation behaved in an apparently normal manner, as regards the changes in cardiac index, although as a group their increases in output were significantly less than the control $(p<0.02)$. Quite conceivably the changes noted in those dogs with denervated hearts manifesting increases in cardiac output in the normal range were nonetheless smaller than they would have been had the autonomic innervation to the heart been intact. Additional evidence indicating the significance of the autonomic nervous system is provided by an analysis of the manner in which the augmentation of cardiac output was achieved. In all of the intact dogs the rise of heart rate contributed more than the elevation of stroke volume to the augmentation of cardiac output. In contrast, in the dogs with denervated hearts, the augmentation of heart rate produced by isovolemic anemia was significantly less and the contribution of an elevated stroke volume was usually of greater importance than in the intact dogs.

The small increases in heart rate that occurred in the dogs with denervated hearts cannot, of course, be explained by any neural mechanism. One possibility for the augmentation of heart rate and cardiac index in the dogs with denervated hearts is a response to circulating catecholamines released from the adrenal medulla. Although the plasma concentrations of epinephrine and norepinephrine in the five denervated dogs in which they were measured did not increase, it could still be argued that since the denervated hearts are supersensitive to circulating catecholamines (21), elevations in plasma levels, too small to be detected, may actually have played a role in the circulatory response to anemia. This possibility was investigated in three dogs with denervated hearts which were also treated with a betaadrenergic blocking agent before the induction of anemia. Inasmuch as receptor blockade would prevent the cardiac action of circulating catecholamines, and since the blockade did not prevent the rise of heart rate and cardiac output consequent 
to anemia, it appears likely that the elevations of these variables observed in the dogs with denervated hearts did not result from circulating catecholamines. In this connection it is also pertinent that the increase in cardiac output produced by anemia is not reduced by prior treatment with dichloroisoproterenol (4), and that after adrenalectomy and ganglionic blockade the cardiac output still rises markedly with the production of anemia (17). Other possible explanations for the elevation of heart rate in the dogs with denervated hearts include: 1) elevation of right atrial pressure, which by increasing the tension of the atrial wall may, as postulated by Blinks (22), increase the rhythmicity of the sinoatrial node, 2) local metabolic changes resulting from the changes in tissue $\mathrm{Po}_{2}$ produced by anemia, and 3) noncatecholamine humoral substances released during anemia.

A possible explanation for the augmentation of cardiac index, which may be applicable to both the intact dogs and to those with denervated hearts, is reflex venoconstriction occurring during anemia. Accordingly, a group of intact dogs was pretreated with reserpine, which has been shown capable of blocking reflex venoconstriction (23) as well as depleting myocardial norepinephrine stores. Although reserpine lowered the control values for cardiac index, heart rate, and minute work, the changes in these variables produced by anemia were similar to those observed in the dogs in which only the hearts had been denervated. Thus, it does not appear that reflex venoconstriction, nor indeed other extracardiac reflexes mediated through the adrenergic nervous system, played a prominent role in the circulatory response to anemia.

The possibility exists that the elevation in cardiac output was the result of stimulation of chemoreceptors consequent to the production of anemia. Since these receptors are sensitive to changes in the partial pressure of oxygen, and since the arterial blood in the anemic period is fully saturated or nearly so, there is no reason to believe that the arterial chemoreceptors are stimulated at this time. Therefore, if chemoreceptors are of importance, they are probably located in the capillary or venous beds. This idea is consistent with the work of Gowdey, who ob- served large increases in cardiac output after the production of methemoglobinemia (24), and of Bartlett and Tenney, who demonstrated that anemia profoundly reduces the tissue oxygen tension in rats (25). Such a reduction in tissue oxygen tension may, however. lower the total systemic resistance through local effects. Thus, arteriolar dilation may result either directly from the hypoxic milieu or from axon reflexes, causing a secondary increase in cardiac output to ensue. These changes might be considered analogous to the opening of a systemic arteriovenous fistula.

The rise in right atrial filling pressure observed after the production of anemia in 13 of 15 animals (Tables I and II) may also play a role in the augmentation of cardiac output, although the cause of this rise in atrial pressure remains uncertain. It seems reasonable to assume, however, that this rise in filling pressure reflects the heart's utilizing the Frank-Starling mechanism and moving up on its ventricular function curve to meet the demands for increased stroke work.

The observations described herein are also of interest in considering the manner in which the heart responds to demands for an increased cardiac output. In the presence of an intact autonomic nervous system the heart of the unanesthetized dog increases output primarily by elevating rate. with relatively small elevations in stroke volume. This response to anemia is similar to that observed when the cardiac output is elevated by muscular exercise (26), and it is likely that the increase in heart rate results largely from alterations in the activity of the autonomic nervous system during stress. As observed in the present investigation, when the organism is deprived of its autonomic nervous system and only minor increases in heart rate can occur. the heart tends to fall back on what might be considered to be a reserve mechanism, namely, an increase in stroke volume.

\section{Summary}

The role of the autonomic nervous system in the circulatory adaptation to acutely induced isovolemic anemia was evaluated by comparing the responses of seven intact unanesthetized dogs with the responses of eight dogs which had been subjected to chronic total cardiac denervation. After 
the induction of severe isovolemic anemia, produced by the exchange of dextran for blood, cardiac output rose markedly in both groups of animals. The rise was significantly greater, however, in the intact dogs than in the cardiac denervated animals. In the intact dogs the increase in cardiac output stemmed predominantly from a rise in heart rate, elevations in stroke volume playing a less important role. In contrast, in the cardiac denervated dogs, the increase in cardiac output tended to be more the result of an augmentation in stroke volume. In an additional four dogs, catecholamine depletion was produced by prior administration of reserpine. These dogs responded in a fashion similar to the cardiac denervated animals in respect to the changes in cardiac index, heart rate, and stroke volume that occurred during anemia, but they displayed smaller increases in cardiac output and in heart rate than the intact dogs. From these results it is concluded that an intact autonomic nervous system is necessary for the total circulatory response to anemia. In the absence of a functioning autonomic nervous system, the organism appears to fall back on what may be looked upon as a reserve mechanism for the augmentation of cardiac output-the elevation of stroke volume.

\section{Acknowledgment}

We would like to thank Dr. Charles A. Chidsey for performing the catecholamine determinations.

\section{References}

1. Brannon, E. S., A. J. Merrill, J. V. Warren, and E. A. Stead, Jr. The cardiac output in patients with chronic anemia as measured by the technique of right atrial catheterization. J. clin. Invest. 1945, 24, 332 .

2. Sunahara, F. A., and L. Beck. Cardiovascular effects of acutely produced anemia in the normal dog. Amer. J. Physiol. 1954, 176, 139.

3. Richardson, T. Q., and A. C. Guyton. Effects of polycythemia and anemia on cardiac output and other circulatory factors. Amer. J. Physiol. 1959, 197, 1167.

4. Gowdey, C. W. Anemia-induced changes in cardiac output in dogs treated with dichloroisoproterenol. Circulat. Res. 1962, 10, 354.
5. Murray, J. F., P. Gold, and B. L. Johnson, Jr. Systemic oxygen transport in induced normovolemic anemia and polycythemia. Amer. J. Physiol. 1962. 203, 720.

6. Heymans, C., and E. Neil. Reflexogenic Areas of the Cardiovascular System. Boston, Little, Brown, 1958.

7. Van Slyke, D. D., and J. M. Neill. The determination of gases in blood and other solutions by vacuum extraction and manometric measurement. J. biol. Chem. 1924, 61, 523.

8. Cooper, T., J. W. Gilbert, Jr., R. D. Bloodwell, and J. R. Crout. Chronic extrinsic cardiac denervation by regional neural ablation. Description of the operation, verification of the denervation, and its effects on myocardial catecholamines. Circulat. Res. 1961, 9, 275.

9. Burn, J. H., and M. J. Rand. The action of sympathomimetic amines in animals treated with reserpine. J. Physiol. (Lond.) 1958, 144, 314.

10. Chidsey, C. A., D. C. Harrison, and E. Braunwald. Release of norepinephrine from the heart by vasoactive amines. Proc. Soc. exp. Biol. (N. Y.) 1962, 109, 488.

11. Gaffney, T. E., E. Braunwald, and T. Cooper. Analysis of the acute circulatory effects of guanethidine and bretylium. Circulat. Res. 1962, 10, 83.

12. Harrison, D. C., C. A. Chidsey, R. Goldman, and E. Braunwald. Relationships between the release and tissue depletion of norepinephrine from the heart by guanethidine and reserpine. Circulat. Res. 1963, 12, 256.

13. Snedecor, G. W. Statistical Methods Applied to Experiments in Agriculture and Biology, 4th ed. Ames, Iowa, Iowa State College Press, 1946.

14. Guyton, A. C., and T. Q. Richardson. Effect of hematocrit on venous return. Circulat. Res. 1961, 9, 157.

15. Sharpey-Schafer, E. P. Cardiac output in severe anaemia. Clin. Sci. 1944, 5, 125.

16. Justus, D. W., R. W. Cornett, and J. D. Hatcher. A humoral influence on cardiovascular adjustments to acute and chronic posthemorrhagic anemia in dogs. Circulat. Res. 1957, 5, 207.

17. Lovegrove, T. D., C. W. Gowdey, and J. A. F. Stevenson. Sympathoadrenal system and response of heart to acute exchange anemia. Circulat. Res. 1957, 5, 659.

18. Harrison, T. R., A. Blalock, C. Pilcher, and C. P. Wilson. The regulation of circulation. VIII. The relative importance of nervous, endocrine and vascular regulation in the response of the cardiac output to anoxemia. Amer. J. Physiol. 1927-28, 83, 284.

19. Nahas, G. G., G. W. Mather, J. D. M. Wargo, and W. L. Adams. Influence of acute hypoxia on sympathectomized and adrenalectomized dogs. Amer. J. Physiol. 1954, 177, 13. 
20. Goodall, McC., and N. Kirshner. Effect of cervicothoracic ganglionectomy on the adrenaline and noradrenaline content in the mammalian heart. J. clin. Invest. 1956, 35, 649.

21. Cooper, T., V. L. Willman, L. T. Potter, and C. R. Hanlon. Responses to sympathomimetic amines after chronic cardiac denervation. Physiologist 1963, 6, 160.

22. Blinks, J. R. Positive chronotropic effect of increasing right atrial pressure in the isolated mammalian heart. Amer. J. Physiol. 1956, 186, 299.
23. Gaffney, T. E., W. M. Bryant, and E. Braunwald. Effects of reserpine and guanethidine on venous reflexes. Circulat. Res. 1962, 11, 889.

24. Gowdey, C. W. Cardiac output in acute experimental methemoglobinemia. Canad. J. Biochem. 1960, 38, 1411.

25. Bartlett, D., Jr., and S. M. Tenney. Tissue gas tensions in experimental anemia. J. appl. Physiol. 1963, 18, 734.

26. Marshall, R. J., and J. T. Shepherd. Exercise and the circulation. Circulation 1963, 27, 323. 